\title{
NOTAS
}

\section{GUILLAUME Y LA CIENGIA DEL LENGUAJE}

Gran parte de la obra que dejó al morir el lingüista francés Gustave Guillaume (1883-1960) está todavía inédita. Pero ésta no es Ia única razón por la que sus ideas han tardado tanto en hallar acogida y siguen siendo tan poco y tan mal conocidas. Teniendo en cuenta las obras ya publicadas (Le problème de l'article et sa solution dans la langue francaise en 1919, Temps et verbe en 1929, L'architectonique du temps dans les langues classiques en 1945 -reeditados los dos últimos en 1965 por Champion- y, por último, una colección dé artículos escritos entre 1933 y 1958 y recogidos en Langage et science du langage, Presses de l'Université Laval, Québec et A. G. Nizet, Paris, 1964), cabe pensar que aparecieron antes de tiempo para ser valoradas como es debido.

Puede considerarse que el período más fecundo de Guillaume se sitúa entre 1938 y 1960. Enseña entonces en la Sorbona (École des Hautes Études) donde da, según los casos, dos o tres conferencias semanales. Los textos de estas conferencias, aproximadamente unas 30000 páginas manuscritas, a las que se suman otras tantas correspondientes a estudios y ensayos varios, han sido donados a Roch Valin, profesor de la Universidad Laval de Québec y depositados en esta Universidad, donde forman el fondo Gustave Guillaume.

En 1964 se inició, bajo la dirección de R. Valin; la labor de transcripción de los varios ciclos de conferencias. Los dos tomos que motivan esta nota son el primer fruto de ese trabajo colectivo ${ }^{1}$. En una advertencia preliminar explica el profesor Valin, responsable de la edición, las normas seguidas así como los criterios que le lian movido a iniciar las publicaciones con las conferencias del año académico 19481949. Una importante introducción del mismo autor presenta sintéticamente el pensamiento de Gustave Guillaume (pp. 9-58).

Aunque corresponde a la segunda serie de conferencias, comenzaré examinando el volumen $\mathrm{B}$, por la importancia y el carácter general de los problemas teóricos en él planteados. Hallamos ahí un nuevo ensayo de tipología lingüística, fundado en el análisis del acto del lenguaje.

En las primeras conferencias se evoca un problema epistemológico

1 Gustave Gulllaume, Legons de linguistigue 1948-1949, publiées par Roch Vali. Vol. A: Structure sémiologique at structure psychique de la langue française, $269 \mathrm{pp}$. Vol. B: Psycho-systématique du language. Principes, méthodes et applications, $222 \mathrm{pp}$. Klincksiek, Paris et Les Presses de I'Université de Laval, Québec, 1972. 
fundamental: cómo se transforma en ciencia teórica una ciencia experimental. Pasar de una a otra supone el reconocimiento de dos cate. gorías de hechos: Ios hechos visibles, de observación directa, a los que globalmente se les suele dar el nombre de "realidad", y otros, profundos que, a pesar de no poderse observar directamente, constituyen aquella realidad cuyo estudio ha de ser el objeto de toda ciencia teórica. El concepto saussuriano de sistema pertenece a ese segundo tipo de realidad, profunda y oculta. De ahí que un sistema lingüístico sea un objeto por construir, cuya edificación, partiendo de los datos de la realidad inmediata, supone un proceso reconstructivo puramente intelectual. Esta postura epistemológica es de suma importancia, pues en ella se funda la ciencia del lenguaje ideada por Guillaume. Tanto las reacciones de incomprensión con que ha chocado esta postura teórica como las críticas que se le siguen dirigiendo se deben a que no se ha querido aceptar que el objeto de estudio -el sistema- tiene que ser construido, o mejor dicho, reconstruido por el lingüista, cosa que sin embargo parece derivarse lógicamente del reconocimiento de los dos tipos de realidad a que nos hemos referido. No dejan de sorprender estas reticencias cuando en otros terrenos científicos, el de la física por ejemplo, ya nadie pone en tela de juicio que la ciencia sea una construcción imaginaria, fundada en una operación reconstructiva de carácter puramente intelectual. En las críticas que Сномsкy dirige al método bloomfieldiano (cf. en particular Aspects of the theory of syntax) encontramos argumentos utilizados veinte años antes por Guillaume, en la denuncia de los límites de una visión estrechamente positivista.

A esa nueva rama de la lingüística cuyo objeto ha de ser el descubrimiento de los sistemas, le da Guillaume el nombre general de sistemática; pero emplea también a veces el neologismo sistemología. La psicosistemática sólo es una parte de la sistemática; como su nombre lo indica, le incumbe el estudio de aquello que, en un sistema, pertenece al significado. Existe otra sistemática, la del significante, o semiología. Veremos, a propósito del tomo A, que es estrecha, según Guillaume, la vinculación entre el sistema psíquico (construcción del pensamiento) y el sistema semiológico (construcción de signos).

Es importante señalar, para terminar con estas observaciones epistemológicas generales que, contra lo que a veces se ha dicho, Guillaume no deja de lado la dimensión histórica. Al contrario, siempre la tiene presente, sólo que reelaborada por entero. En el eje de las sucesividades, la pricomecánica no considera hechos aislados, como solía hacerlo la morfología tradicional, sino que toma en cuenta la evolución de los enteros sistemáticos. Guillaume esboza con esto una historia que en gran parte está por hacer: la historia de los sistemas. Más concretamente, en el tomo que estamos reseñando, intenta mostrar las relacio nes que median entre la naturaleza del lenguaje y su historia.

Saussure veía la lengua como un sistema. Guillaume ve en ella, además, un sistema que integra sistemas integrados ("un système intégrant de systèmes intégrés”). El primer sistema, cuyo análisis es capital, pues de él depende todo futuro avance, es el formado por la lengua y el discurso en el seno del acto del lenguaje. Hay que advertir que 
dicha dicotomía no corresponde al binomio estático de lengua-habla de Saussure, ni al de competence-performance de Chomsky. No es posible extenderme aqui sobre un tema que ha sido y sigue siendo tan debatido. Me limitaré a indicar que, para Guillaume, el acto del lenguaje es en todo idioma una actividad del espíritu que integra en un todo sistemático la lengua, cuyo momento de construcción no alcanza nuestra observación, y el discurso, momentáneamente edificado a partir de los materiales que la lengua pone a su disposición. Nos hallamos, por lo tanto, frente a dos operaciones de construcción, sistemáticamente ordenadas una en relación a otra, a las que corresponden tiempos distintos, lo cual se puede representar con el siguiente esquema, en el que I simboliza la integridad del proceso y $U$ el umbral entre las dos fases de la operación:

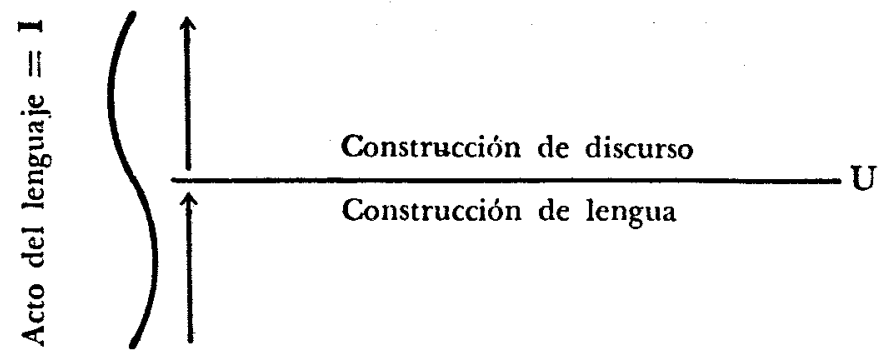

Tenemos aquí una característica universal del lenguaje. Ahora bien: según Guillaume la partición entre el hecho de lengua y el hecho de discurso no se da nunca de un modo idéntico en las distintas lenguas naturales; además, conforme avanza la historia del lenguaje, el umbral separador de ambas operaciones varía. De modo que, por medio del acto del lenguaje, Guillaume llega a plantear el problema de toda la tipología lingüística.

El desarrollo de dicha tipología se realiza, en efecto, entre dos estructuras-límite teóricas. En el primer caso, la construcción de la lengua está reducida a lo mínimo, y en cambio, el discurso es objeto de un máximo desarrollo. En el segundo caso, sucede al revés: la construcción de la lengua alcanza un máximo de desarrollo, con lo cual se reduce proporcionalmente la del discurso. Las lenguas aislantes, como el chino antiguo, representan el primer caso de estructura-límite. En ellas la lengua se halla reducida a los elementos formadores, cuya ensambladura se remite al discurso. En las lenguas flexivas, al contrario, la construcción del discurso se ve más o menos reducida, en beneficio de la de la lengua.

Entre ambos polos se dan casos intermedios. Sólo daré una idea somera de las principales articulaciones distinguidas por Guillaume en su análisis. En la representación gráfica reproducida más arriba, el acto del lenguaje está animado por un cinetismo ascendente, que se impone a todo locutor cuando construye oraciones $=$ unidades efectivas (unités d'effet), a partir de unidades preconstruidas $=$ unidades potenciales (unités de puissance) de las que el hablante es portador. En realidad, en el acto del lenguaje intervienen dos movimientos: uno descendente, 
disociativo, orientado de lo ancho a lo estrecho, constructor de la lengua; otro ascendente, asociativo, orientado de lo estrecho a lo ancho, constructor del discurso. Este doble movimiento se inscribe entre dos límites. Guillaume llama al primero la aprehensión radical (saisie radicale); éste es el que permite aprehender, en el nivel más profundo del acto del lenguaje, los elementos formadores. El segundo límite, llamado por él aprehensión oracional (saisie phrastique) desemboca en la construcción de la unidad efectiva: la oración. Entre estos dos extremos se sitúa la aprehensión léxica (saisie lexicale), generadora de la unidad potencial, según el caso, carácter o vocablo; la característica fundamental de esta aprehensión léxica es su movilidad a lo largo del eje del lenguaje:
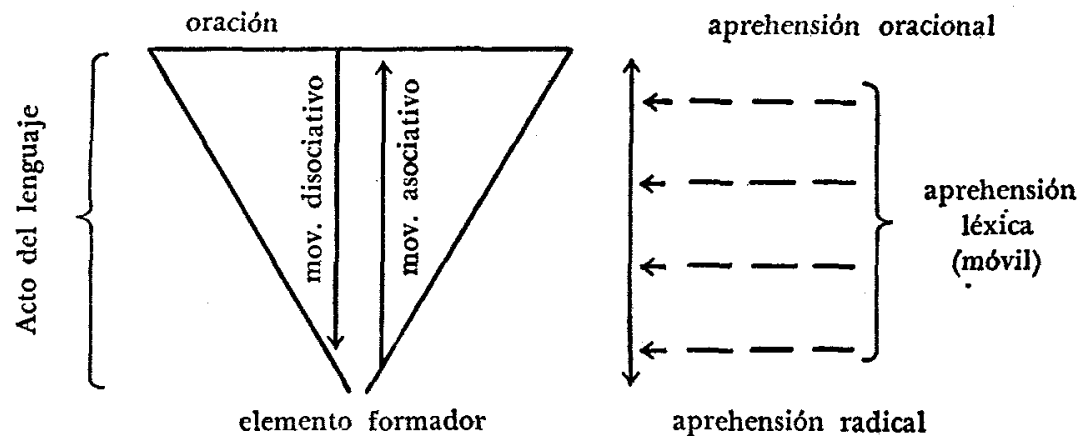

aprehensión radical

Se aprecia la importancia de tal movilidad, teniendo en cuenta que la tipología de una lengua depende del momento en que la aprehensión léxica intercepta el acto del lenguaje. Un primer tipo de lenguas, próximo según cabe suponer a la primitiva originalidad -a propósito de la que Guillaume emite con grandes reservas unas hipótesis-, corresponde a una intercepción tardia, que coincide entonces con la aprehensión oracional. El resultado es una lengua holofrástica, como las lenguas amerindias, o como algunas europeas (vasco, húngaro, turco) con modificaciones más o menos importantes del mecanismo primitivo. Inversamente, por medio de una intercepción precoz del acto del lenguaje, se identifican aprehensión léxica y aprehensión radical. Resulta entonces una unidad potencial reducida al elemento formador, como en las lenguas aislantes.

Las lenguas flexivas se sitúan entre ambos extremos. En ellas, el momento en que la aprehensión léxica intercepta el acto del lenguaje puede variar, aunque siempre guarda una distancia relativa tanto de la aprehensión radical como de la aprehensión oracional. De esta variación depende el grado de construcción morfológica del vocablo. Conforme se separa la aprehensión léxica de la aprehensión oracional, disminuye la morfología integrada al vocablo, de modo que la constitución interna del vocablo depende de las intersecciones del eje constructor del acto del lenguaje.

Entre las lenguas en las que la aprehensión léxica no coincide ni con la aprehensión oracional ni con la aprehensión radical, merecen 
un lugar aparte las lenguas semíticas de raíces pluriconsonánticas. En ellas, la base psíquica del vocablo resulta de un proceso en el que intervienen dos aprehensiones léxicas sucesivas: la primera, de movimiento ascendente, y producida por un alejamiento de la aprehensión radical, engendra la raíz, portadora de matière notionnelle, o sea, de una idea general difluyente (p. ej. k-t-b evoca la noción general de "escribir"); la segunda, que viene a limitarla formalmente, se edifica inversamente por un alejamiento de la aprehensión oracional; está representada por la inserción de vocales morfológicas (katib 'el que escribe', kitab 'lo que se escribe).

Guillaume identifica varios tipos lingüísticos a través de análisis muy penetrantes, vinculados todos, según hemos indicado, a la nueva teoría del vocablo. Señalemos en particular los dedicados al vasco (sobre todo en las conferencias que van del 20 de enero al 24 de febrero) : se defiende ahí la idea de que en vasco "la palabra es una frase universalizada por el traslado, fuera de ella, de sus elementos particulares".

A partir del 10 de marzo, Guillaume centra su estudio en las lenguas que poseen partes de la oración (sin dejar de lado las comparaciones con otros tipos lingüísticos), y estudia la economía del vocablo indoeuropeo. Éste, al tener por término una universalización integrante, aparece como vocablo cerrado, comparadócon el vocablo abierto de las lenguas aislantes. Pasa después a estudiar la formación de las partes de la oración, donde destaca la importancia, en su génesis, del mecanismo de incidencia. Este mecanismo, desatendido por las demás escuelas lingüísticas, y que había sido presentado sólo de un modo esquemático en los trabajos publicados anteriormente, recibe aquí un tratamiento detallado. Se entiende por incidencia la manifestación de una relación muy general, establecida entre un aporte (apport) y un soporte (support). En las lenguas en las que existen partes de la oración, el vocablo es un aporte de significación en busca de un soporte; de la relación entre aporte y soporte depende la categoría a la que pertenece el vocablo. En el análisis de los mecanismos de incidencia Guillaume evoca problemas de gran importancia: el régimen de incidencia de la preposición, la distinción entre adjetivo y verbo, el empleo copulativo del auxiliar "être" y, en las últimas conferencias sobre todo, la transitividad del verbo en su relación con el mecanismo de la voz. Hay que hacer notar que, a pesar de la particularidad de estos problemas, Guillaume nunca pierde de vista su propósito inicial: la construcción del vocablo en la historia general del lenguaje.

El tomo A trata problemas relativos al francés, casi todos estudiados ya por Guillaume en otros artículos. Sin embargo, el carácter de gran generalidad de los principios metodológicos expuestos y la amplitud de las conclusiones hacen que el interés de este tomo rebase el de un estudio particular. La obra de Guillaume se distingue precisamente por esa capacidad generalizadora.

Como lo indica el título, se dedica este ciclo de conferencias al estudio de la doble estructura del francés, más exactamente a la relación existente entre la estructura semiológica, la del significante en el sentido saussuriano de la palabra, y la estructura psíquica, la del signifi- 
cado. Para emplear palabras de Guillaume, todo idioma es en efecto "una obra construida en el pensamiento a la cual se superpone una obra construida en signos" y es peligroso, por lo tanto, disociar el estudio de una parte y la otra. La estructura psíquica o sistema representado (en este caso el sistema verbal) satisface, según Guillaume, la exigencia de máxima coherencia, mientras que la estructura semiológica, o sistema representativo, sólo satisface a la exigencia de adecuación suficiente al sistema representado. De aquí saca Guillaume un principio metodológico de gran importania, al afirmar que sólo cabe estudiar la semiología de una lengua en relación con los mecanismos psíquicos subyacentes que esta semiología pone de manifiesto; pero, desde el punto de vista del observador, es evidente que sólo se llega al psiquismo subyacente por medio de la semiología. La primera labor que le incumbe al lingüista es, pues, la de reconstruir los enteros sistemáticos a partir de las articulaciones del sistema, únicas significantes. Puede citarse, a título de ejemplo, el análisis consagrado a los tres radicales del verbo aller, resumen de un artículo reproducido en Langage et science du langage.

El entero sistemático estudiado por Guillaume en las conferencias del año 1948-1949 es la cronogénesis, que brevemente puede definirse como la operación mediante la cual es posible representar espacialmente la imagen del tiempo (spatialisation de l'image-temps). Se impone, en efecto, el recurso de una representación espacial, dada la imposibilidad radical de representar el tiempo (siempre implícito en el verbo) a través de medios temporales. He aquí una representación simplificada de la cronogénesis.

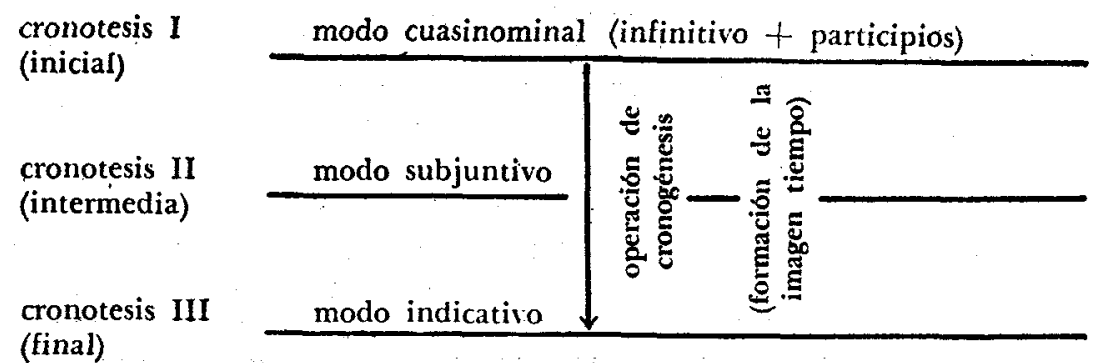

Guillaume se contenta con exponer brevemente la teoría de los modos², con aplicación a los tres modos del francés y estudia especialmente su contenido formal. Sitúa al indicativo como término de la operación de cronogénesis, puesto que es el que da la imagen más acabada del tiempo (el hecho de incluir el presente trae como consecuencia la distinción entre dos épocas, pasada y futura). Son muy interesantes sus comentarios sobre las diferentes posibilidades de visualizar el tiempo, sobre la relación existente entre el tiempo y la persona y, por último, sobre las nociones de incidencia y decadencia, fundamentales para el análisis del contenido temporal de los tiempos de indicativo.

Según promete el título, el paralelismo entre psiquismo y semiolo-

2 La cronogénesis había sido estudiada extensamente en Temps et verbe, 1929. 
gía se ilustra con numerosos ejemplos. Creo que es especialmente convincente al respecto el análisis de la estructura semiológica del imperfecto de subjuntivo (pp. 97 ss.), del subjuntivo en general (pp. 243-248) y del futuro de indicativo (pp. 551 ss.).

Luego de haber propuesto una teoría general de los modos referidos al sistema, es decir a la lengua, Guillaume estudia sus varios empleos en el discurso. En este sentido el subjuntivo recibe una atención especial. El subjuntivo representa un imperfecto, en la medida en que es ideado antes de que llegue a su término el proceso constructivo de la imagen-tiempo. Se evocan, a título de comprobación experimental, numerosos casos de empleo.

Según Guillaume, es un error metodológico grave considerar que el subjuntivo es esencialmente el modo de la subordinación, ya que son numerosas, las subordinadas construidas con indicativo. Lo importante, en los casos de subordinación, o sea cuando se expresa integralmente la relación idée regardante (je préfère) / idée regardée (qu'il vienne), es apreciar correctamente la categoría a la que pertenece l'idée regardante y fijar donde se sitúa el umbral modal (seuil modal) que rige la construcción con un modo o con otro. En francés, según demuestra Guillaume, dicho umbral se sitúa entre las nociones de posible y probable. Toda idée regardante categorizable dentro de los límites de lo posible rige una oración subordinada con empleo de subjuntivo, mientras que toda idée regardante categorizable como perteneciente a lo probable (y, huelga decirlo, a lo cierto), rige una subordinada con indicativo. Es decir:

UMBRAT. MODAL

Il est possible qu'il vienne

Il est probable qu'il viendra

Il est certain qu'il viendra subjuntivo

indicativo

De ahí que rijan subjuntivo los verbos y las locuciones que expresan la espera, el deseo y, de un modo general, la ponderación crítica puesto que corresponden a idées regardantes situadas más acá del umbral separador. De una correcta apreciación de las idées regardantes depende toda la teoría discursiva de los empleos del subjuntivo. El problema se reduce pues a una cuestión de enfoque o visée, como decía Guillaume en Temps et verbe.

El umbral modal varía según los idiomas. En español, por ejemplo, contrariamente a lo que pasa en francés, la extensión del subjuntivo es mayor, pues abarca también la idea de probabilidad (es probable que venga).

En realidad, lo que hace Guillaume en el análisis que acabo de presentar es mostrar cómo se genera el subjuntivo y cómo se genera el indicativo. Cabe decir, por lo tanto, sin abusar de la extensión de la palabra, que la psicomecánica aparece aquí como un método eminentemente generativo.

Con esto no quedan planteados todos los problemas que trata Guillaume en las conferencias de este primer tomo. Remito a quien desee convencerse de su variedad al índice general. 
Como he indicado más arriba, el texto de las conferencias va precedido de una densa introducción de Roch Valin. Precisamente en razón de su densidad, he preferido reservarla como epílogo. El autor ofrece en ella una visión de conjunto de la teoría guillaumiana, con el valioso aporte personal de un análisis detallado de la noción de tiempo operativo (temps opératif), básica para la comprensión de la psicomecánica a menudo mal interpretada. A propósito del tiempo operativo, estudia Valin el problema general de la relación entre tiempo y lenguaje, y critica especialmente las consecuencias de la ruptura introducida por Saussure entre diacronia y sincronia. No creo exagerado afirmar que esta introducción puede considerarse como uno de los textos claves de la psicomecánica.

También queda dicho que estos dos tomos inician una serie de publicaciones. Otro tomo de conferencias del mismo año (1948-49, Serie C) y una antología destinada a ilustrar los aspectos principales de la teoría guillaumiana han sido publicados ya (Klincksiek, París, 1973). Me limitaré a agregar que las reiteraciones e insistencias propias del estilo hablado que hallamos en las conferencias facilitan notablemente la comprensión de una doctrina a menudo reputada difícil, por la gran densidad y la concisión que caracterizan los trabajos de Guillaume publicados antes. Didácticamente esta publicación ofrece, pues, la gran ventaja de poner al alcance del lector cultivado una teoría que representa una contribución de primer orden al movimiento científico contemporáneo.

Université de Lille III.

Monique JoLy

\section{HAGIA UNA DEFINICION EMPIRIGA DE LA ALITERACIÓN}

Los alumnos insatisfechos son el recurso natural más importante que tiene el investigador. Este trabajo se debe a que un alumno me pidió que le explicara qué cosa era la aliteración. Yo le di la definición que aparece en todos los manuales de la literatura: es la "repetición de un mismo sonido, vocal o consonante, a lo largo de un enuniado"1. Es "una repetición de ciertas consonantes o grupos de sonidos"2. Es una "figura que se comete empleando en una cláusula voces en que frecuentemente se repiten una o unas mismas letras"3. "¿Esto vale para todas las consonantes o sólo para algunas?" me preguntó el alumno. "No sé”, le contesté. El alumno no cejó. "¿Cuántas repeticiones tiene que haber para que haya aliteración?" "No sé", tuve que admitir otra vez. 'Y esto de la aliteración sólo vale para los comienzos de las palabras?" "No tengo ni idea", fue la contestación, pero ya no en tono avergonzado, sino interesado. "A ver si lo podemos averiguar".

1 E. Correa Calderón y F. Lázaro Carreter, Cómo se comenta un texto lite. rario (Madrid, 1966).

2 Vox, Diccionario manual ilustrado de la lengua española, Barcelona, 1970.

3 Diccionario de la Real Academia Española. 